\title{
KEMUNGKINAN PENERAPAN PROFIT EQUALIZATION RESERVE (PER) PERBANKAN SYARIAH DALAM TINJAUAN FIQIH DI INDONESIA
}

\section{POSSIBLE APPLICATION OF PROFIT EQUALIZATION RESERVE (PER) ISLAMIC BANKING IN REVIEW FIQH IN INDONESIA}

\author{
M.Rofi Udin N.F ${ }^{1}$, Rully Trihantana ${ }^{2}$ \\ ${ }_{1}^{1}$ Jurusan Ekonomi Islam Fakultas Ekonomi Islam Universitas Djuanda, Jl. Tol Ciawi No. 1, Kotak Pos \\ 35 Bogor 16770. \\ ${ }_{2}^{2} J u r u s a n$ Perbankan Syariah Fakultas Ekonomi Islam Universitas Djuanda, Jl. Tol Ciawi No. 1, Kotak \\ Pos 35 Bogor 16770
}

(DiterimaolehDewanRedaksi:16-02-2014)

(Dipublikasikan oleh Dewan Redaksi:01-06-2015 )

\begin{abstract}
Islamic Banking in relation to the efforts to overcome the "fund flight", the current issue has been circulating about an instrument that is used to overcome the losses that Profit Equalization Reserve (PER). The goal is the implementation Knowing PER (Profit Equalization Reserve) on Islamic banking in the review of jurisprudence. Knowing the possibility of the application of the PER (Profit Equalization Reserve) on Islamic banking in Indonesia.The method used in this research is descriptive qualitative research, the data used in this study is primary data and secondary data. Primary data is data relating to the application of the PER (Profit Equalization Reserve) in Islamic banking. Based on this research, that the instrument PER (Profit Equalization Reserve) is included in mashlahah mursalah because there is no proof that the ban but ordered and beneficial and not contrary to the arguments of Shar'i. so that the instrument PER (Profit Equalization Reserve) may be possible to apply but must be approved Islamic bank customers first before creating PER (Profit Equalization Reserve) and the end of the period of Islamic banks must distribute these funds to customers of the fair.
\end{abstract}

Keywords : Profit Equalization Reserve, Mudharaba Contract

\begin{abstract}
ABSTRAK
Sehubungan dengan upaya Bank Syariah mengatasi terjadinya "fund flight", maka saat ini telah beredar isu mengenai sebuah instrumen yang digunakan untuk mengatasi kerugian tersebut yaitu Profit Equalization Reserve (PER).Tujuan yang ingin dicapai adalah Mengetahui penerapan PER (Profit Equalization Reserve) pada perbankan syariah dalam tinjauan fiqih. Mengetahui kemungkinan penerapan PER (Profit Equalization Reserve) pada perbankan syariah di Indonesia.Metode yang digunakan pada penelitian ini adalah penelitian deskriptif kualitatif, data yang digunakan pada penelitian ini adalah data primer dan data sekunder. Data primer adalah data yang berhubungan dengan penerapan PER (Profit Equalization Reserve) di perbankan syariah. Berdasarkan hasil penelitian, bahwa instrumen PER (Profit Equalization Reserve) ini termasuk pada mashlahah mursalah karena belum ada dalil yang memerintahkan dan melarangnya namun bermanfaat dan tidak bertentangan dengan dalil syar'i. sehingga instrumen PER (Profit Equalization Reserve) ini dapat dimungkinkan untuk diterapkan namun bank syariah harus mendapat persetujuan nasabah terlebih dahulu sebelum menciptakan PER (Profit
\end{abstract}


Equalization Reserve) dan diakhir periode bank syariah harus mendistribusikan dana tersebut kepada nasabah dengan adil.

Kata Kunci : Profit Equalization Reserve, kontrak Mudharabah

M.Rofi Udin N.F. 2014. Kemungkinan Penempatan Profit Equalization (PER) Perbankan Syariah Tinjauan Fiqih di Indonesia (1): 54- 61.

\section{PENDAHULUAN}

Perbankan syariah merupakan industri keuangan Islam yang dalam beberapa tahun terakhir ini telah meramaikan persaingan dalam industri keuangan didunia khususnya di, Indonesia. Dalam kurun waktu 5 tahun terakhir, pertumbuhan perbankan syariah konsisten berada di kisaran 38 - 45 persen yoy (year on year) (Sholihin, 2014).

Perkembangan yang begitu signifikan, perbankan syariah memiliki kebutuhan akan sebuah kebijakan untuk membantu mengintegrasikan keuangan Islam dalam sistem keuangan nasional dan global. Secara khusus, desain dan implementasi Basel II yang standarnya setara untuk Bank Syariah dan penerapan sistem manajemen risiko yang efektif, yang mencerminkan fitur operasional khusus keuangan Islam. Walaupun IFSB (Islamic Financial Service Board) telah mengeluarkan berbagai standar kehati-hatian dan pedoman yang sejalan dengan Basel II dan juga cocok dengan sistem keuangan Islam, penerapan standar ini memerlukan pendekatan pengukuran risiko yang baru. Khususnya, sebuah isu penting dalam pengelolaan risiko oleh Bank Syariah secara global, adalah bagaimana mengukur dan mengelola risiko yang berkarakteristik bagi hasil (mudharabah), yang merupakan salah satu sumber pendanaan Bank Syariah.

Mudharabah merupakan salah satu sumber pendanaan pada Bank Syariah yang mana pembiayaan tersebut termasuk dalam beberapa pembiayaan yang diminati oleh masyarakat, karena sistem dari mudharabah adalah akad kerjasama usaha antara dua pihak, dimana pihak pertama bertindak sebagai pemilik dana (shohibul maal) yang menyediakan seluruh modal
(100\%), sedangkan pihak lainnya sebagai pengelola usaha (mudharib).

Dengan banyaknya masyarakat yang menggunakan akad mudharabah pada pembiayaannya maka Bank Syariah akan berpikir mengenai risiko apa yang akan dihadapi, karena pada setiap pengelolaan dana pada Bank Syariah memiliki risiko yang harus dihadapi. Begitu juga dengan mudharabah, pembiayaan ini memiliki beberapa risiko yang harus dihadapi termasuk didalamnya adalah kerugian.

Jika terjadi kerugian pada usaha yang dijalankan maka Bank Syariah selaku mudharib tidak dapat membagi hasil dari usaha tersebut dan nasabah yang mana disini sebagai shohibul maal pun tidak mendapatkan bagi hasilnya, karena seperti yang kita ketahui bahwa bagi hasil pada akad mudharabah adalah berfluktuasi yang mengacu pada hasil dari usaha yang didapat. Dan kejadian inilah (kerugian) yang akan menjadi masalah, karena di khawatirkan bagi mereka yang belum sepenuhnya paham mengenai akad tersebut akan membeda-bedakan dengan Bank Konvensional dan merasa tidak puas dengan kinerja Bank Syariah, kemudian hal yang paling di khawatirkan adalah terjadinya "fund flight" yang cukup besar dari Bank Syariah ke Bank Konvensional, dikarenakan suku bunga Bank Konvensional lebih tinggi di banding imbal hasil Bank Syariah.

Sehubungan dengan upaya Bank Syariah dalam mengatasi terjadinya "fund flight", maka saat ini telah beredar isu tentang sebuah instrumen yang digunakan untuk mengatasi kerugian tersebut. Isu yang beredar adalah mengenai PER (Profit Equalization Reserve), yaitu sebuah cadangan yang dibuat oleh Bank Islam dengan mengambil alih jumlah tertentu dari laba mudharabah, sebelum 
mengalokasikan porsi mudarib dan shobibul maal.

Pada mulanya PER (Profit Equalization Reserve) telah diperbolehkan untuk digunakan pada Bank-Bank Syariah di Malaysia sekitar 12 tahun yang lalu. PER disetujui oleh Dewan Syariah Nasional Bank Negara Malaysia (BNM) setelah mendapat rekomendasi dari Association of Islamic Banking Institution Malaysia (AIBIM) yang ditujukan untuk memitigasi disparitas/perbedaan laba simpanan/suku bunga antara Bank-Bank Syariah/Unit Usaha Syariah dan Bank-Bank Konvensional. Kemudian, Setelah beberapa tahun PER telah dijalankan oleh perbankan syariah di Malaysia dan menjadi isu di perbankan syariah di Indonesia, maka timbul sebuah pertanyaan di kalangan penggiat ekonomi Islam bahwa apakah instrumen PER ini telah sesuai dengan unsur-unsur dalam tinjauan fiqih ?, dan apakah PER ini benar-benar diperbolehkan untuk di praktekan pada perbankan Syariah di Indonesia?.

Berdasarkan uraian diatas perumusan masalah pada penelitian disini adalah :

1. Bagaimana tinjauan fiqih terhadap PER (Profit Equalization Reserve) pada perbankan syariah?

2. Apakah PER (Profit Equalization Reserve) pada perbankan syariah dimungkinkan penerapannya di Indonesia?

\section{MATERI DAN METODE}

Metode yang digunakan pada penelitian ini adalah penelitian deskriptif kualitatif, data yang digunakan pada penelitian ini adalah data primer dan data sekunder. Data primer adalah data yang berhubungan dengan penerapan PER (Profit Equalization Reserve) di perbankan syariah, sedangkan data sekunder adalah data pendukung yang diperoleh dari berbagai literatur baik textbook, majalah, surat kabar, internet dan yang memiliki keterkaitan dengan penelitian ini. Teknik pengambilan data dalam penelitian ini melalui teknik analisis dokumen yaitu dengan mengambil data PER (Profit Equalization Reserve) pada perbankan syariah yang telah menerapkan, kemudian teknik wawancara yaitu melakukan interview secara langsung dengan praktisi ekonomi Islam mengenai penerapan PER (Profit Equalization Reserve) serta teknik kepustakaan yaitu mengambil data yang berkaitan dengan penelitian dari sumber-sumber seperti buku-buku, majalah, artikel, surat kabar dan sebagainya.

Teknik analisis data yang digunakan adalah analisis kualitatif, dimana analisis berdasarkan data yang diperoleh, selanjutnya dikembangkan pola hubungan tertentu atau hipotesis. Berdasarkan hipotesis yang dirumuskan berdasarkan data tersebut, selanjutnya dicarikan lagi secara berulang-ulang sehingga selanjutnya dapat disimpulkan, apakah hipotesis tersebut diterima atau ditolak berdasarkan data yang terkumpulkan. Bila berdasarkan data yang dapat dikumpulkan secara berulang-ulang ternyata hipotesis diterima maka hipotesis tersebut berkembang menjadi teori ( Sugiyono, 2010 ).

\section{HASIL DAN PEMBAHASAN}

1. Tinjauan Fiqih Terhadap PER (ProfitEqualization Reserve)

Dalam menetukan hukum Islam, para ulama menggunakan maqashid syariah atau mashlahah untuk mencari kemashlahatan yang terkandung didalam permasalahan yang sedang dihadapi, artinya maqashid syariah atau mashlahah adalah untuk mewujudkan kemashlahatankemashlahatan manusia dengan memenuhi kebutuhan lima pokok penting (agama, jiwa, akal, keturunan dan harta). (Agustianto, 2013).

Adapun jika dilihat dari tingkatan pada mashlahah, para ulama ushul fiqih telah membagi menjadi 3 tingkatan (Agustianto, 2013) :

a) Mashlahah Dharuriyat Yaitu kemashlahatan yang keberadaannya 
dibutuhkan oleh kehidupan manusia, baik tentang agama maupun dunia. Artinya manusia tidak dapat tegak tanpa 5 kebutuhan dasar tersebut (agama, jiwa, akal, keturunan dan harta)

b) Mashlahah Hajjiyat

Yaitu kemashlahatan yang keberadaannya menghilangkan manusia, namun jika kemashlahatan ini diabaikan, tidak merusak kehidupan (kebutuhan), tetapi akan menimbulkan kesulitan.

c) Mashlahah Tahsiniyat

Yaitu kemashlahatan yang keberadaannya untuk mendukung dan melengkapi kemashlahatan yang lain dan ketiadaannya tidak langsung merusak penjagaanterhadap agama, jiwa, keturunan dan harta.

Dari pembagian mashlahah berdasarkan tingkatnya, maka instrumen PER (Profit Equalization Reserve) masuk pada mashlahah tingkat tiga yaitu mashlahah tahsiniyat, dimana keberadaan instrumen PER (Profit Equalization Reserve) ini merupakan pendukung dan pelengkap yang digunakan dalam memitigasi risiko yang bertujuan untuk mempertahankan tingkat pengembalian yang sebanding dengan tarif bunga bank konvensional. Namun jika instrumen tersebut tidak digunakan, maka hal ini tidak langsung merusak 5 kebutuhan dasar manusia yaitu agama, jiwa, akal, keturunan dan harta dan juga tidak langsung merusak lalulintas sistem mudharabah pada perbankan syariah.

Sedangkan, jika kita lihat dari segi ada dan tidak adanya oleh syar'i, maka mashlahah ini terbagi menjadi tiga (Agustianto, 2013) :

a) Mashlahah Mu'tabarah

Yaitu mashlahah yang perintahnya bersumber dari Al-qur'an maupun hadist seperti perintah shalat, puasa ramadhan.

b) Mashlahah Mulghah

Yaitu mashlahah yang ditolak legalitasnya oleh nash syara', baik Al-qur'an maupun hadis. Artinya sesuatu yang dianggap bermanfaat akan tetapi bertentangan dengan syar'i seperti meminum minuman keras.

c) Maslahah Mursalah

Yaitu mashlahah yang tidak terdapat nash yang memerintahkannya atau melarangnya, kemashlahatannya terlepas dari dalil. Mashlahah tersebut tidak diperintah dalam Al-qur'an dan hadis, akan tetapi tidak bertentangan dengan keduanya.

Diantara ketiga bentuk mashlahah diatas, instrumen PER (Profit Equalization Reserve) lebih sesuai pada mashlahah mursalah, karena didalam Al-qur'an dan hadis tidak terdapat dalil yang memerintahkan instrumen PER (Profit Equalization Reserve) ini.

Sesuai dengan mashlahah mursalah, instrumen PER (Profit Equalization Reserve) ini dapat diterapkan, dengan syarat tidak bertentangan dengan nash baik Al-qur'an dan hadis. Namun instrumen PER (Profit Equalization Reserve) ini dapat bertentangan dengan syar'i jika hal yang terpenting dalam perbankan syariah tidak dilakukan, yaitu bank syariah diharuskan untuk memperoleh persetujuan dari pemilik rekening investasi terlebih dahulu untuk menerapkan mekanisme PER (Profit Equalization Reserve), karena jika bank syariah tidak 
memperoleh persetujuan terlebih dahulu dari pemegang rekening investasi maka akan menimbulkan ketidakadilan bagi pemegang rekening investasi, yang mana mereka tidak mendapat bagi hasil yang penuh karena dana mereka telah dikurangi oleh bank syariah untuk menciptakan PER (Profit Equalization Reserve), dan perbuatan ini (mengurangi hak manusia) termasuk pada firman Allah Subhanahu Wa ta'ala yang artinya :

"Dan janganlah kamu merugikan manusia pada hakhaknya dan janganlah kamu merajalela di muka bumi dengan membuat kerusakan."(QS. AsSyuara' : 183)

Juga firman Allah dalam surat Huud yang artinya :

"Dan Syu'aib berkata: "Hai kaumku, cukupkanlah takaran dan timbangan dengan adil, dan janganlah kamu merugikan manusia terhadap hak-hak mereka dan janganlah kamu membuat kejahatan di muka bumi dengan membuat kerusakan."(QS : Huud : 85)

Dari ayat-ayat diatas dapat kita lihat bahwa Allah Subhanahu Wa Ta'ala melarang hambanya untuk merugikan manusia pada hak-haknya. Jika kita perhatikan pada instrumen PER (Profit Equalization Reserve), hal tersebut dapat saja terjadi yakni merugikan manusia pada hak-haknya yaitu dimana dengan diterapkannya instrumen ini bank syariah mengambil sebagian dana bagi hasil dari pemegang rekening investasi yang mana pengambilan tersebut tanpa seizin pemilik rekening investasi, walaupun pada akhirnya akan dikembalikan, namun akan tetap merugikan bagi nasabah/ pemegang rekening investasi karena memang tidak semua nasabah menerima hal tersebut. Maka sangat diperlukan adanya persetujuan dari nasabah/ pemegang rekening investasi mengenai penerapan mekanisme PER (Profit Equalization Reserve) pada bank syariah untuk menanggulangi adanya ketidak adilan yang dirasakan oleh nasabah/ pemegang rekening investasi.

Meminta persetujuan disini dapat dikatakan dengan meminta izin, dan dalam hal ini meminta izin kepada pemilik rekening investasi sebelum menciptakan rekening PER (Profit Equalization Reserve) diqiyaskan dengan meminta izin sebelum memasuki rumah seseorang karena dua hal tersebut sama-sama ingin menggunakan kepemilikan orang lain dan harus mendapatkan izin terlebih dahulu dari pemiliknya, jadi disini berlaku firman Allah yang artinya :

"Hai orang-orang yang beriman, janganlah kamu memasuki rumah yang bukan rumahmu sebelum meminta izin dan memberi salam kepada penghuninya. yang demikian itu lebih baik bagimu, agar kamu (selalu) ingat."(QS. An-Nuur : 27)

Dan firman Allah Subhanahu Wa Ta'ala yang artinya :

"Sesungguhnya yang sebenarbenar orang mukmin ialah orangorang yang beriman kepada Allah dan Rasul-Nya, dan apabila mereka berada bersama-sama Rasulullah dalam sesuatu urusan yang memerlukan pertemuan, mereka tidak meninggalkan (Rasulullah) sebelum meminta izin kepadanya. Sesungguhnya orang-orang yang meminta izin kepadamu (Muhammad) mereka Itulah orang-orang yang beriman kepada Allah dan Rasul-Nya, Maka apabila mereka meminta izin kepadamu karena sesuatu keperluan, berilah izin kepada siapa yang kamu kehendaki di antara mereka, dan mohonkanlah ampunan untuk mereka kepada Allah. Sesungguhnya Allah Maha Pengampun lagi Maha Penyayang." (QS. An-Nuur : 62)

Dan sabda Rasulullah Shallallahu 'Alaihi Wa Sallam : 


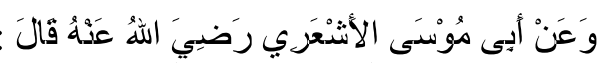

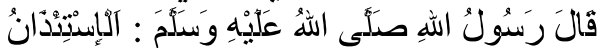

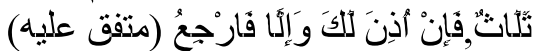

Artinya : "Dari Abu Musa AlAsy'ari Radhiyallahu 'anhu berkata : Rasulullah Shallallahu 'alaihi wa sallam bersabda: "Permintaan izin itu tiga kali, jika diberikan izin kepadamu maka kamu boleh masuk dan jika tidak maka kamu harus pulang." (Muttafaq 'alaih)

Dari dua ayat dan hadis diatas dapat kita temukan bahwa kita dianjurkan untuk meminta izin terlebih dahulu sebelum menggunakan hak milik orang lain, sama halnya dengan instrumen PER (Profit Equalization Reserve) yang harus memperoleh izin terlebih dahulu dari nasabah/ pemegang rekening investasi sebelum menciptakan rekening PER (Profit Equalization Reserve), hal ini dilakukan agar terjadi keadilan diantara semua pihak baik pihak nasabah/ pemegang rekening investasi atau pihak bank syariah.

Kemudian setelah bank syariah mendapat persetujuan dan menciptakan rekening PER (Profit Equalization Reserve), maka pada akhir periode atau ketika dana tersebut akan dikembalikan, bank syariah harus mendistribusikan keuntungan yang didapat dengan adil kepada pemegang rekening investasi, seperti dalam firman Allah yang artinya :

"Dan Syu'aib berkata: "Hai kaumku, cukupkanlah takaran dan timbangan dengan adil, dan janganlah kamu merugikan manusia terhadap hak-hak mereka dan janganlah kamu membuat kejahatan di muka bumi dengan membuat kerusakan."(QS : Huud : 85)

Ayat diatas memerintahkan kita untuk berlaku adil dan tidak merugikan manusia atau dalam hal ini adalah nasabah/ pemegeng rekening investasi. Jadi bank syariah selain harus meminta persetujuan tapi juga harus mendistribusikan keuntungannya dengan adil kepada pemegang rekening investasi.

Berdasarkan hasil wawancara dengan Dr. Ahmad Subagyo, SE. MM. CRBD sebagai praktisi ekonomi Islam mengenai kemungkinan penerapan instrumen PER, beliau menyatakan bahwa penerapan instrumen PER ini diperlukan dalam bank syariah karena digunakan untuk mengendalikan risiko yang akan dihadapi oleh bank syariah. Beliau juga menyatakan bahwa instrumen PER (Profit equalization Reserve) dalam terminologi konvensional hampir sama dengan CKPN (Cadangan kerugian penurunan nilai) penerapannya berdasarkan PBI No.14 tahun 2012 yang mengacu pada PSAK no. 55 dan PAPI (konven) PAPSI (Pedoman Akuntansi Perbankan Syariah Indonesia) tahun 2013. Maka dari penjelasan ini dapat lihat bahwa instrumen PER dapat diterapkan di Indonesia. kebolehan penerapan instrumen PER ini dikuatkan dengan Asas Kebebasan Berkontrak didalam hukum perdata/ hukum ekonomi/ hukum perbankan yang mana didalamnya menjelaskan kebolehan memasukkan ketentuan PER didalam kontrak perbankan. Menurut hemat peneliti hal ini PER bisa diterapkan di Indonesia terlebih saat ini bank syariah di Indonesia relatif masih baru dan belum masing relatif belum kuat dalam mengahadapi risiko.

Melihat mekanisme PER (Profit Equalization Reserve) yang diterapkan di Malaysia maka dimungkinkan penerapannya di Indonesia dengan beberapa penyesuaian tentunya dengan menyesuaikan produk-produk perbankan syariah di Indonesia. 


\section{KESIMPULAN DAN IMPLIKASI}

\begin{tabular}{l}
\multicolumn{4}{c}{ Berdasarkan uraian penelitian } \\
diatas mengenai r kemungkinan \\
penerapan Profit Equalization Reserve \\
(PER) perbankan syariah $r$ dalam \\
tinjauan fiqih di Indonesia, maka \\
penulis dapat menarik kesimpulan \\
sebagai berikut:
\end{tabular}

a) Berdasarkan tingkatan pada mashlahahnya, maka instrumen PER (Profit Equalization Reserve) ini masuk pada mashlahah tahsiniyat, yang mana kemashlahatan pada mashlahah ini merupakan pelengkap dan pendukung bagi kemashlahatan yang lain dan ketiadaannya tidak merusak 5 kebutuhan dasar manusia antara lain agama, jiwa, akal, keturunan dan harta. Jadi instrumen PER (Profit Equalization Reserve) tidak harus dilakukan atau diterapkan karena memang tidak termasuk pada tingkat yang darurat yang mengharuskan bank syariah untuk menerapkannya.

b) Dari segi ada dan tidaknya dalil syar'inya maka instrumen PER (Profit Equalization Reserve) ini termasuk pada mashlahah mursalah karena memang instrumen PER ini belum ada dalil syar'i yang memerintahkan secara khusus atau melarangnya secara khusus akan tetapi mengandung manfaat bagi kedua belah pihak (pemegang rekening investasi dan Bank Syariah), dan tidak bertentangan dengan dalil-dalil lain karena itulah instrumen ini masuk dalam kategori mashlahah mursalah.

c) Bank syariah diharuskan untuk meminta persetujuan/ izin kepada nasabah/ pemegang rekening investasi seperti yang diqiyaskan dengan meminta izin sebelum memasuki rumah orang lain, sesuai firman Allah yang artinya :

"Hai orang-orang yang beriman, janganlah kamu memasuki rumah yang bukan rumahmu sebelum meminta izin dan memberi salam kepada penghuninya. yang demikian itu lebih baik bagimu, agar kamu (selalu) ingat." (QS. An-Nuur : 27)

Dan ayat yang ada pada QS. An-Nuur : 62, yang isinya sama-sama menganjurkan untuk meminta izin terlebih dahulu sebelum menggunakan hak milik orang lain.

d) Tinjauan fiqih terhadap instrumen PER (Profit Equalization Reserve) pada perbankan syariah adalah memungkinkan untuk diterapkan, instrumen PER ini sifatnya hanya diperbolehkan untuk diterapkan dan tidak sampai pada tingkat yang harus untuk diterapkan, karena instrumen ini hanyalah suatu pelengkap dan pendukung untuk kemashlahatan lainnya juga ketiadaannya tidak langsung merusak 5 kebutuhan dasar manusia.

e) Instrumen PER (Profit Equalization Reserve) ini diperbolehkan untuk diterapkan dengan syarat yaitu harus dengan persetujuan/ perizinan dari nasabah atau pemegang rekening investasi, jika persyaratan tersebut tidak dilakukan maka instrumen PER (Profit Equalization Reserve) ini tidak boleh untuk diterapkan karena akan merugikan pihak lain.

f) Bank Syariah harus adil dalam mendistribusikan kembali dana dari rekening PER (Profit Equalization Reserve) kepada nasabah/ pemegang rekening investasi.

g) Melihat mekanisme PER (Profit Equalization Reserve) yang diterapkan di Malaysia maka dimungkinkan penerapannya di Indonesia dengan beberapa penyesuaian tentunya dengan menyesuaikan produk-produk perbankan syariah di Indonesia.

a) Bank syariah sebaiknya mengajukan surat kepada Dewan Syariah Nasional (DSN) untuk mengeluarkan fatwa tentang penerapan PER (Profit 
Equalization Reserve) perbankan syariah di Indonesia.

b) Jika fatwa mengenai PER (Profit Equalization Reserve) tersebut telah keluar maka diharapkan untuk segera dipublikasikan agar perbankan syariah di Indonesia dapat dengan jelas mengetahui kejelasan mengenai instrumen tersebut.

c) Bank syariah sebaiknya mengajukan surat kepada Bank Indonesia (BI) untuk mengeluarkan Peraturan Bank Indonesia (PBI) mengenai perhitungan PER di perbankan syariah Indonesia.

d) Dalam meminta persetujuan atau perizinan dari nasabah atau pemegang rekening investasi, bank syariah dapat menawarkan kepada nasabah/ pemegang rekening investasi mengenai metode PER (Profit Equalization Reserve) pada saat pembukaan rekening baru, dan disana bank syariah juga harus menjelaskan kepada nasabah mengenai mekanisme PER (Profit Equalization Reserve) ini.

\section{DAFTAR PUSTAKA}

Generic and Specific Terms Condition For All Islamic Deposit Accounts/ Products/ Services of Affin Islamic Bank.

Guidelines on Profit Equalization reserve, Islamic Banking And Takaful Departement, Bank Negara Malaysia.

Ifham Ahmad, Sholihin. Keuntungan Memilih Bank Syariah. Diunduh dari www.ahmadifham.com tanggal 01 januari 2014.

In Islamic Banks (An article: V. Sundararajan,Director, Centennial Group Holdings LLC, Washington DC).

Issues in Managing Profit Equalization Reserve and Investment Risk Reserve

Minka, Agustianto. 2013. Maqashid Syariah Dalam Ekonomi Islam Dan Keuangan Syariah, Jakarta: Ikatan Ahli Ekonomi Islam.
Profit Equalization Reserve versus investment risk reserve. Di unduh dari www.Invesment-and-Finance.net pada tanggal 01 januari 2014

Sugiyono. 2010. Metode Penelitian Bisnis, Bandung : ALFABETA. 